\title{
Socio-cultural design as a means of moral education of schoolchildren in the conditions of modern education
}

\section{El diseño sociocultural como medio de educación moral de los escolares en las condiciones de la educación moderna}

\author{
Irina Aryabkina \\ aryabkina68@inbox.ru \\ https://orcid.org/0000-0002-8765-2153 \\ Doctor of pedagogical sciences, professor, Ulyanovsk State Pedagogical University, \\ Ulyanovsk State University, Russian Federation. \\ Irina Medvedeva \\ https://orcid.org/0000-0003-3132-4078 \\ Doctor of pedagogical sciences, Dean of the Faculty of Art and Music Education, \\ Chuvash State Pedagogical University, Russian Federation. \\ Alexander Bulynin \\ https://orcid.org/0000-0001-6107-2997 \\ Doctor of pedagogical sciences, professor, Ulyanovsk State University, Russian \\ Federation. \\ Natalia Lebedeva \\ https://orcid.org/0000-0001-8260-3371 \\ Doctor of pedagogical sciences, professor, Federal State Budgetary Educational \\ Institution of Higher Education "Moscow State Linguistic University", Russian \\ Federation. \\ Galina Zharkova \\ https://orcid.org/0000-0002-5561-5219 \\ Doctor of pedagogical sciences, professor, Ulyanovsk State University, Russian \\ Federation.
}

\section{Abstract}

Recibido: $27 / 08 / 21$

Aceptado: 10/11/21

The purpose of the article is to analyze the features of socio-culturnal design as a means of moral education of schoolchildren in the context of modern education. On the basis of an interdisciplinary analysis of scientific sources, the essence of socio-cultural design, its principles and role in the formation of the moral qualities of the younger generation are determined. The article presents the materials of a psychological and pedagogical experiment to determine the level of moral education of schoolchildren of different ages, as well as the pedagogical conditions identified and formulated by the authors in the form 
of conclusions. The proposed diagnostic tools made it possible to determine the effectiveness of the application in educational practice of the Program for the sociocultural design of schoolchildren developed by the authors of this article.

Key Words: socio-cultural design, moral education, schoolchildren, modern education.

\section{Resumen}

El propósito del artículo es analizar las características del diseño sociocultural como medio de educación moral de los escolares en el contexto de la educación moderna. Sobre la base de un análisis interdisciplinario de fuentes científicas, se determina la esencia del diseño sociocultural, sus principios y papel en la formación de las cualidades morales de la generación más joven. El artículo presenta los materiales de un experimento psicológico y pedagógico para determinar el nivel de educación moral de escolares de diferentes edades, así como las condiciones pedagógicas identificadas y formuladas por los autores en forma de conclusiones. Las herramientas de diagnóstico propuestas permitieron determinar la efectividad de la aplicación en la práctica educativa del Programa para el diseño sociocultural de escolares desarrollado por los autores de este artículo.

Palabras clave: diseño sociocultural, educación moral, escolares, educación moderna.

\section{Introduction}

In the conditions of technologization and informatization of all social life, it is especially important that education solves the task of forming moral qualities of a person. To do this, it is necessary to apply innovative forms, content and methods of education, a combination of new technologies and practical methods aimed at developing the subjectivity of the student as a creative, responsible and moral person.

Socio-cultural design is a specific technology, which is a constructive, creative activity, the essence of which is to analyze problems and identify the causes of their occurrence, develop goals and objectives, develop ways and means to achieve goals.

Socio-cultural design means the solution by means of culture of various social problems in situations of their maximum uncertainty and a very large number of their possible solutions. Socio-cultural design is aimed at creating models for solving specific tasks that have serious social significance, allowing you to develop models of what "should happen" with the use of available resources. That is why the training of the younger generation in socio-cultural design at different levels of the educational system is becoming so obviously relevant today that it actualizes the need to analyze the theoretical and philosophical foundations of socio-cultural design in modern education. 


\section{Theoretical framework}

To solve the problem posed in this study, it is necessary to consider socio-cultural design as a concept that integrates various concepts ("project", " design ", "project activity", "social design ", "culture"), and then identify its impact on the moral education of schoolchildren in modern education.

First of all, it is necessary to find out what the term "project" is.

On the one hand, the project is a way of expressing tasks, ideas, actions aimed at achieving the intended goals, taking into account the necessary resources for the practical implementation of the plans.

On the other hand, the project is a special symbolic form of displaying the interests, needs, aspirations and attitudes of people, aimed at transforming their surrounding reality: nature, society, themselves.

The correlation of these definitions allows us to conclude that the project should be understood as a form of displaying ideas and aspirations of people, allowing them to manage activities provided they correctly set goals, develop steps for its implementation and implementation.

Under the design is today it is customary to understand the process of creating a prototype project, a prototype of an assumed or possible object, state.

Design is the process of developing and implementing a useful, socially significant product and has two main features: the ideal nature of the action and its focus on the appearance (formation) of something in the future. These features distinguish social design from other types and types of humanitarian technologies (for example, from research).

Project activity belongs to the category of innovative creative activity, since this type of activity involves the transformation of reality and is based on the appropriate technology, which can not only be mastered, but also improved.

Social design is one of the leading ways of modern organization of public life, management of society. Regardless of what kind of objects are being designed, they bear the features of the value-normative system of the initiator of the project.

Some scientists consider social design as a form of social management; scientifically based design of a system of parameters of a future social object or a qualitatively new state of an existing object (Genisaretsky, 1986). 
Social design is one of the activities for the formation of a volumetric-informational analogue (project) of the social object being created. Social design as planning performs its specific functions in the development of a social object; at the same time, it should be taken into account that the plan determines the sequence of activities to achieve the result, and the project contains the necessary constructive characteristics of activities for the implementation of goals and objectives.

Thus, social design is an innovative method of social management in demand by modern reality, characterized by a focus on activities that transform society in the future. For the organization of social design, a detailed study of the scope and object of design is required, based on the selection of the most appropriate design principles for the intended goals and objectives.

To define the essence of the concept of "socio-cultural design", it is necessary to refer to the concept of "culture". This term originates in Ancient Rome and comes from Lat. Culture ("cultivation", "development", "veneration"). Today, this term has a lot of definitions. Let's consider some of those that are directly related to the subject of this study.

Culture in a broad sense can be defined as a way of organizing and developing human life and, at the same time, as its result. This concept includes everything created by people, the whole set of products of human activity, social forms of organization, processes, institutions, everything that has already been done, is being done and will be done by man in the future.

In a narrower sense, culture is a combination of the spiritual and material values of this society at a given period of time (Bulavina, 2007).

One of the options for defining culture may be this: culture is a behavior inherent specifically to a reasonable person, considered in an inextricable connection with material objects used as an instrumental part of this behavior.

The transformations of modern society and culture are based on the values that underlie modernist projects with their attempts to streamline symbolic forms and a system of social ties.

How can we comprehend the concept of "social design" from the standpoint of culture, i.e. come to an understanding of the essence of socio-cultural design?

Many modern scientists (Aryabkina, 2016; Markov \& Birzhenyuk, 1997; Mikheeva, 2008, etc.) believe that the system of knowledge, experience, relationships, traditions developing in time and space as the "quintessence" of culture can be described in terms of social design, since design is a fundamental characteristic of culture and a mechanism of social inheritance. 
Sociocultural design refers to a promising, on the one hand, and formalized, on the other hand, a kind of human activity for the transformation of cultural objects. Socio-cultural design is the realization of a person's ability to create in an ideal plan, to combine symbolic constructions (Bulavina, 2007).

In essence, socio-cultural design is a technology for solving problems in conditions of maximum uncertainty of tasks and variability of their possible solutions.

The analysis of the above-mentioned concepts allows us to conclude that socio-cultural design is a technology that allows us to qualitatively change the state of cultural development of different social groups, directly affect the position of certain cultural objects. This phenomenon is characterized by the need for a thorough study of the subject of design and its interaction with the environment, a clear statement of tasks and determination of steps for their implementation.

Socio-cultural design, of course, can be attributed to the category of complex knowledgeintensive technologies that combine the technologies of a number of sciences and at the same time are characterized by their own design tools. Working on a socio-cultural project, it is necessary to diagnose the existing problem from all sides, identifying the sources and nature of the existing shortcomings. It is necessary to find and work out various solutions to the existing problem, taking into account the resources that are available. Next, you need to choose the most optimal solution to the problem and arrange it in the form of a socio-cultural project. And finally, to develop mechanisms for the implementation of the project in social practice and to determine the material, technical, financial, legal conditions that ensure its implementation.

Thus, the socio-cultural project is a kind of target block implemented through a system of practical measures. At the heart of generating a project idea and developing conditions and ways of its implementation is a system of principles, i.e., "basic starting points, theoretical and ideological foundations and the most general standards of project activity" (State Pedagogical University, 2015).

Socio-cultural design should be based on the following principles

1) The principle of "critical modification threshold".

The implementation of this principle is based on taking into account the boundaries and possibilities of controllability of the object of socio-cultural design, the degree of correctability of socio-cultural processes and the assessment of socially significant consequences of such modifications. The basis for this principle is the idea of the possibilities and limits of intervention in the functioning of socio-cultural systems, since every complex system contains many ways of development that correspond to its nature (State Pedagogical University, 2015). 
This principle seems to be the most significant at present, since its implementation makes it possible to maximize the energy of self-development of culture, while limiting the possibilities of administrative and incompetent interference in cultural life. In practice, it means providing the subjects of socio-cultural life with maximum organizational and legal independence, refusing violent transformation leading to the destruction of nature, man, the world, but most importantly - creating conditions for self-organization and selfdevelopment of the subject of socio-cultural life.

It follows from this fact that the semantic guidelines of design are not in the strict management of cultural processes or the development of culture in the sense of industry, infrastructure, but in the support of a self-organizing socio-cultural environment for which culture is a universal and pervading component.

2) The principle of optimization of the "zone of the nearest development" of the personality - the socio-cultural environment of its habitat.

The essence of this principle is that one of the main design guidelines is the selfdevelopment of a socio-cultural subject, which is understood as a person, community or society as a whole. For the success of socio-cultural design, it is important to develop conditions that would promote self-development by solving or preventing problems associated with unfavorable life circumstances.

In this regard, an essential aspect of the content of the socio-cultural project is the optimization of the human habitat, fundamental in socio-cultural design is the creation of conditions that would stimulate the personal development of each member of society.

The theoretical basis of this principle is the cultural and historical concept of personality development as a communication-mediated process of mastering and appropriation of cultural values by an individual. The "core" of this concept is the idea of L.S. Vygotsky about the development of personality as a cultural and historical process, his thoughts about the importance of art in the development of personality, about the "cultural ascent" and expansion of personality by mastering oneself through the sign and the text of culture, by overcoming the contradiction between the individual psychological and culturalhistorical (Vygotsky, 1984).

According to the cultural and historical concept of personality development (Vygotsky, 2000), the richness of individuality is determined and ensured by the influence of historically developing culture; the success of socialization and individualization of personality is mediated by its socio-cultural context; at the same time, as an object of optimization of these processes, the zone of proximal development is considered, namely the socio-cultural environment as the leading space of human habitation, a condition for the formation and realization of its potentials.

In this regard, an urgent task of modern education is the optimization of the zone of immediate personal development, which is vital for the full development of cultural space. 
Cultural space is currently understood as everything that surrounds a person on a daily basis. It is multidimensional and dynamic, pulsates and breathes like a living organism. Its content and quality have a direct impact on the spiritual world of the individual, the way of life of a person. Semantic and symbolic components of cultural space inevitably play the role of a reference point in value preferences, form a sense of family closeness, kinship of its constituent people, motivate the behavior of people in a wide range.

The socio-cultural environment is thus a multidimensional hierarchically constructed system education, which includes: the physical world, the system of existing relations between people and public institutions; culture, traditions and customs; "space" or "a set of public activities", conditions of direct life and chronotype.

A teacher in the conditions of modern education should take into account the influence of the socio-cultural environment on the development of the student's personality, on the formation of his moral qualities. At the same time, the socio-cultural environment should have a number of characteristics:

- stability;

- the ability to mutually connect different spaces in which the student's life takes place;

- The ability to encourage rather than prohibit activities;

- appropriateness, meaningfulness of all types of activities in which the student is included;

- the ability to encourage students to creative manifestations, self-realization, the embodiment of themselves and their aspirations;

- sufficient diversity and richness of various elements of the environment, encouraging the student to make a choice and giving the opportunity to find their socio-cultural niche;

- orientation to generally accepted general cultural norms and values, which the student takes for granted, which is a necessary condition.

The environment and socio-cultural environment affect the younger generation as a combination of social and natural conditions.

Note that the socio-cultural environment can have not only a positive, but also a negative impact on the human personality. Researchers have proved that the socio-cultural environment is capable of both shaping and deforming a person, filling or emptying (depending on what a person selects from it and what he opposes). For a child as a person at the stage of formation, the impact of the socio-cultural environment is a determining factor in his personal development.

In philosophy, the socio-cultural environment is defined as a combination of three components: 
1. Megaenvironment - the modern social world surrounding a person, which determines the spiritual and socio-psychological atmosphere of the epoch. Here, the factors that form the personality of the student include the conditions of existence and the culture of all mankind, the culture that stores the programs of activity and communication in the form of various sign systems, "distributing" which a person becomes cultured.

2. Macroenvironment - the society, the country to which the individual belongs. The influence of the macro environment is very great. The macro-environment ensures the transfer of the cultural experience of one's country, native people through such factors as mass media and social institutions (kindergarten, school, cultural institutions).

3. Microenvironment - the immediate environment of the child in the person of three main groups: family, academic staff, friends. The specifics of each of these groups are determined by age differences (Khuzina, 1996).

Thus, the socio-cultural environment is understood as the totality of social and spiritual factors and conditions directly surrounding a person in the process of his life. The emphasis on the optimization of the socio-cultural environment is due to the fact that it is a fundamental factor determining human values, norms, ideals, etc.

The implementation of the principle of optimization of the zone of immediate personal development can be considered a practical embodiment of the environmental approach to socio-cultural design.

3) The principle of personification of the process and results of socio-cultural design.

This principle is based on free self-realization, the possibility of implementing and introducing alternative projects and ideas by means of cultural activities. It is known that without a person's self-activity, without his active assimilation of social norms and ideals, it is impossible to translate social values into personal ones.

The characterized principle also presupposes the restoration of the connection of cultural processes with the personality of the creator, the actualization of moral referents hidden in the national and world history.

It should be noted that this principle is based on a person's perception of culture as a special spiritual world and on understanding the problems of cultural development as a certain contradiction between the existing and desired value systems. This world is filled with images, meanings, ideas, and values that are significant for a particular person.

4) The principle of optimal orientation towards preservation and change (the proportionality of traditional and innovative mechanisms and processes of cultural dynamics).

The optimal correlation between the processes of reproduction of cultural heritage (actualization, demand for phenomena already existing in culture or pre-existing phenomena, values, norms, traditions, etc.) and the processes of cultural innovation presupposes the unconditional dominance of the first trend. Culture as a system of 
accepted norms is something that opposes development, since it preserves and maintains the stability of the ontological picture of the world, is derived from it and creates normative institutions for its consolidation (Sycheva, 2004).

Consequently, within the framework of cultural development programs, the predominant orientation should be towards preservation (values, traditions, forms of life, etc.), i.e., the reproduction of culture as an integral and organic system, including the past, present and future on equal terms.

Change is a function of civilization, information technology culture, but not spiritual, humanitarian culture. This means that in the context of socio-cultural design, the most productive worldview is conservative, traditionally oriented. The task of the designer is to achieve the organicity of the human cultural environment through the project - by preserving, saving and recreating elements of culture as an integral system.

5) The principle of problem-target orientation is the leading technological principle of socio-cultural design. It implies, first of all, the targeted orientation of programs to solve specific problems, the carriers of which are a person, a social group, a certain territory or region, society as a whole; their focus on the self-realization of individuals and social groups, on the self-realization of a person in the socio-cultural sphere.

This principle is manifested and implemented at various stages of design in the form of:

- analysis of the main pain points and problems;

- search for various non-standard ways and ways to solve them;

- search for sources of financing and resources;

- involvement of all interested subjects of socio-cultural life in the project implementation process (State Pedagogical University, 2015).

The implementation of this principle requires teachers to have a broader understanding of the sphere of culture, significantly increases the range of cultural policy and the object area of design, shifts the focus from leisure issues to the development of culture in the broad sense of the word.

The organizational and managerial essence of this design principle lies in the need to find appropriate social forces interested in solving certain problems. And in the structure of cultural policy, each group of problems should have an addressee who verbalizes, evaluates and reflects them in the form of positions and goal-oriented solutions (including within the framework of a socio-cultural project).

The relevance of the problem-target principle of design is due to: understanding culture in a broad social context - as a system that covers all spheres of human activity; expanding the boundaries of culture as an object of cultural policy, i.e. going beyond leisure and moving to the design of cultural development processes in the broad sense 
of the word; the need to abandon a rigid regulatory management system and transition to a "soft" regulatory system by providing appropriate conditions.

The advantages of this principle are as follows.

Firstly, there is no need for ineffective sociological research, which is also often quite lengthy and costly.

By virtue of this principle, problems are in the first place among the factors that need to be taken into account, and interests and needs act as something secondary. Of course, they are taken into account in the development and implementation of programs, but their role is such that the already available information about the interests and needs of various categories of the population, obtained earlier in the course of sociological studies conducted in almost every region, is quite sufficient. For a full-fledged study of the content block of the project, it is necessary first of all to know the problems that are typical for the social group acting as the audience of the program.

Secondly, the orientation of socio-cultural programs to solve a wide range of problems expands the field of socio-cultural activities, strengthens the social significance and prestige of culturological and socio-pedagogical professions (both in the eyes of the population and representatives of the mass media, public organizations, parties, government structures), guarantees their social relevance.

Thirdly, the problem orientation of projects and programs activates the participation of those to whom they are addressed - due to the correspondence of human interests and the target setting of the project.

More specific principles of socio-cultural design (mainly of a technological nature) are:

- the principle of proportionality of the projected changes, i.e. their compliance with the physiological, mental, environmental and socio-cultural nature of the person acting as the primary structural element of the project audience;

- the principle of social and personal expediency, the implementation of which consists in achieving compliance of the expected results with normative goals and personal needs, the development of organizational forms of experimental verification and the introduction of the most socially effective option from the proposed design solutions;

- the principle of complexity, which involves taking into account all the main directions and forms of human interaction with his natural, social and cultural environment;

- the principle of realism, which requires solving culturally significant problems based on real, measurable and usable resources (economic, personnel, information); calculating the economic feasibility and social effectiveness of the project; maximizing the use of positive ways already available in culture to solve similar or identical problems; attitude to innovation as a consistent modification of existing cultural patterns; substantiation of the limits of applicability and replicability of the project. 
Thus, the fundamental principles of design are:

- the principle of the critical threshold of modification;

- the principle of optimization of the zone of immediate development;

- the principle of personification of the design process and results;

- the principle of optimal orientation to conservation and change;

- the principle of problem-target orientation;

- as well as the principles of proportionality of projected changes, social and personal expediency, complexity and realism.

These principles of socio-cultural design perform a twofold function: firstly, they determine the worldview of the designer, as well as the style and moral intonation of the concepts, projects, programs, initiatives developed by him, i.e. they provide a value-oriented level of design (especially the first four principles). According to the degree of their implementation (in the target and content part of the project), one can judge the organicity of the program, the extent of its creativity or destructiveness. Secondly, these principles form the theoretical basis of the technology of socio-cultural design, which will be disclosed in the following sections of the manual.

Socio-cultural design in our study is considered as a means of moral education of the emerging personality. According to numerous studies carried out by educators, sociologists, cultural scientists and psychologists, there are some metamorphoses in the consciousness of a modern person (such as the development of social pessimism, deterioration of social well-being, loss of internal guidelines of behavior and an increase in aggressiveness, tension). The research results show that society has proved unable to protect the child from the negative influence of the media and the lack of positive guidelines. A modern child develops in conditions of socio-cultural deprivation, when his most basic needs for cultural development, leisure, and socially approved means of selfrealization are not met.

At the same time, in the modern socio-cultural situation, a special type of personality is in demand - free, autonomous, responsible, with a reflexive consciousness, capable of self-organization and self-development. This type of personality sets the target for modern education. Society dictates the need for the formation of a socio-cultural young person, therefore, modern education should be considered from the standpoint of specific pedagogical activity aimed at creating effective conditions for the development and selfdevelopment of the student, as well as opportunities for his free creative expression (Kotova \& Afanasyeva, 2017; Troshin, 2016, etc.).

One of the fundamental characteristics of the "man of culture" is his ability to cognitive activity, i.e. productive imagination, creative and free transformation of reality based on his cultural needs. Modern cultural studies considers cultural and leisure activities as a process of creating conditions for a person's motivational choice of subject activity, and this process is also determined by the cultural needs of the individual, her interests. 
The cultural needs of the individual are actually the human principle in a person, the focus of national values (beauty, goodness, truth, etc.) and means of life (ideas about the surrounding world and reality, ways of actively influencing the "second nature", manifestations of an emotional and evaluative attitude to what is happening in the "zone of proximal development"). In this regard, it is not accidental that researchers turn to a culturological approach when designing a socio-cultural space (Kolinko, 2011).

During the formation of a student's moral culture, such main forming personality traits as imagination and artistic and aesthetic creativity based on it, arbitrariness in the form of the ability to act independently, the child's need to actively act in the world are born and developed. On the other hand, cognitive needs correspond to transformative activity, value-oriented activity corresponds to value-oriented needs, communicative activity corresponds to communicative needs, etc., but they are all components of cultural needs (Rozhkov \& Bayborodova, 2002).

It is important to note that the formation of social needs acquires a fully vital character, becomes an imperative of development. The complication of social ties reveals to a growing person the true content of the phenomenon of freedom as a key concept for characterizing the social sphere of being. Dependence on the actions of adults and the search for opportunities for personal self-affirmation are the launching pad for a much more complex process - self-determination among peers (Lipsky \& Sikorskaya, 2013).

The discovery of one's "I" is made precisely in the socio-cultural sphere, and the emerging stereotypes of behavior in different situations begin to form the "core" of the personality the cultural needs and culture of the child, and also lays down moral values.

Thus, socio-cultural activity in the form of socio-cultural projects in modern educational organizations should be aimed at satisfying cultural needs and interests, at the formation of moral qualities of the child. The comprehensive development of the child's personality is the goal of such activities, during which the student acquires the ability to socialize and adapt to different aspects of society; the external form of socio-cultural activity (as a result of self-reflection and self-identification) turns into the internal transformative activity of children, forms moral values.

At the heart of any project activity is the development of cognitive skills, the ability to independently design their knowledge, navigate the information space; the development of critical and creative thinking (State Pedagogical University, 2015). The practice of implementing socio-cultural projects can be considered as a special area of educational activity, extracurricular or extracurricular work, closely related to the main educational process and focused on the development of research, creative activity of children, as well as on deepening and consolidating their existing knowledge, skills and upbringing of moral qualities of the individual. This work is carried out individually or by a large group of children, and the terms of work on the project can also be different. Socio-cultural projects can have different durations. 
Design training allows you to educate an independent and responsible personality, develops individuality, creativity and mental abilities of children, and, what is especially important in the modern world, promotes the education of their moral qualities, forms the right attitude to others. It is this kind of active activity that makes it possible to shift the focus from the process of passive accumulation of the amount of knowledge by students to mastering them in various ways of activity in conditions of availability of information resources, which contributes to the active formation of a creative personality capable of solving non-traditional tasks in non-standard conditions.

While preparing to work on a socio-cultural project, the student must understand that he is studying the culture of the country. If these are features of national culture, then it is necessary to learn more about the people who own certain cultural values. The student should realize that, for example, Russia is a multinational country, and each culture is an important part of the culture of his native country. In the process of working on the project, students form ideas about good and evil, about the correctness of actions, about the possibility of choosing actions, which, of course, contributes to the moral education of children.

The optimal relationship between the processes of reproduction of cultural heritage (actualization, demand for phenomena already existing in culture or pre-existing phenomena, values, norms, traditions, etc.) and the processes of cultural innovation presupposes the unconditional dominance of the first trend. Culture as a system of accepted norms is something that opposes development, since it preserves and maintains the stability of the ontological picture of the world, is derived from it and creates normative institutions for its consolidation.

Consequently, within the framework of cultural development programs, the predominant orientation should be towards preservation (values, traditions, forms of life, etc.), i.e., the reproduction of culture as an integral and organic system, including the past, present and future on equal terms.

If we consider the project activity on the part of the student, then it is an opportunity to maximize the disclosure of his creative potential. This is an activity that will allow you to express yourself individually or in a group, try your hand, apply your knowledge, benefit, show publicly the result achieved, gain invaluable experience in communicating with new people. This is an activity aimed at solving an interesting problem, often formulated by the students themselves in the form of a task, when the result of this activity - the found way to solve the problem is practical, has important applied significance and, most importantly, is interesting and significant for the "discoverers" themselves, starting from a young age (Matyash \& Simonenko, 2007; Zabbarova, 2017).

Socially significant project activity is a modern effective pedagogical technology. It allows each of its participants not in words, but in fact to feel significant, necessary, successful, able to overcome various problematic situations. Its peculiarity is that it makes it possible 
for every student to be successful, and this regardless of abilities, inclinations, character traits, socio-cultural design in the conditions of a modern school is considered as an integrative activity that synthesizes elements of gaming, cognitive, value-oriented, transformative, labor, communicative, educational, theoretical and practical activities.

One of the main features of project activity is that it unfolds in a problematic situation that is not solved by direct action.

The second feature of the implementation of socio-cultural projects is that their participants must be motivated. That is, in the project activity, not only the understanding of the problem should be realized, but also the very idea of the child.

The third important feature of such a design is its targeted nature. Since in the course of project activity the child expresses his attitude and personal meanings, he is always looking for the addressee - the person to whom his statement is addressed, framed in the form of a product. That is why project activity has a pronounced social connotation, and ultimately is one of the few socially significant actions available to a student.

The unity of children and adults on the basis of common interests makes them equal participants in communication, between whom trusting relationships develop, which contributes to the formation of moral ideals and the formation of a positive self-esteem in the child: "I myself!", "I could!", "I know!"

The subject of socio-cultural projects can be related to the subject content; it should have a practical orientation, affect the extracurricular interests of children. These can be both short-term individual projects and long-term collective multi-projects. The topics of the projects can be extremely diverse: helping nature, others, preserving natural monuments, getting to know the cultural values of the people, solving environmental problems.

Working in socio-cultural projects, students gain invaluable experience from communicating with interesting people. By visiting cultural objects and performing the tasks set by the project, children enrich themselves and acquire concepts of moral values. Creative projects that involve the appropriate design of their results in the form of drawings, presentations, works of decorative and applied art, baby books, albums and so on are in great demand at the moment.

It is advisable to conduct excursions, observation walks, social actions (surveys, interviews, etc.) with students in the process of working on the project. Of course, it is very important to create positive emotions in students in the process of socio-cultural design, then the effect of participation in this important activity will be greatest.

\section{Methodology}

In our work, theoretical (analysis of psychological, pedagogical, methodological literature; theoretical generalization of research results) and empirical (observation - direct and 
included, conversation, questionnaire, pedagogical experiment, processing of the data obtained) research methods were used.

To identify the effectiveness of the use of socio-cultural design as a means of moral education in modern educational practice, we have defined the criteria of moral education of younger schoolchildren (formation of moral concepts; moral self-esteem; ethics of behavior (tolerant behavior); moral motivation) and selected diagnostic methods to determine the levels of moral education of students (Pakhomov, 2012; Doronina \& Korol, 2015).

\section{Results}

The interdisciplinary analysis of scientific literature carried out by us made it possible to develop and introduce into the educational practice of five schools of the Russian Federation (Ulyanovsk, Cheboksary and Moscow) a program of socio-cultural design for schoolchildren of different ages. 355 schoolchildren of different ages took part in the pedagogical experiment.

During the implementation of this program, its effectiveness was monitored according to the criteria and with the help of diagnostic techniques specified above.

The monitoring results indicate that, in almost every group of students included in our experiment, according to all four criteria identified by us, there was a positive dynamics in the levels of moral education of students (the greatest effect from the introduction of the Socio-cultural Design Program (in $85 \%$ of cases) we observed in primary school students, less pronounced performance in secondary school (the level of moral education in this age group of students increased by $64.7 \%$ ). In high school, there are quite high results regarding the influence of socio-cultural design on the level of moral education of students (about 70\%), which is explained by the greater awareness of 15-17-year-old schoolchildren of the social effects of their practical socio-cultural activities.

\section{Conclusion}

Moral education of the younger generation is one of the most difficult and, at the same time, urgent tasks of pedagogical science. For its successful solution, the teacher should possess a whole range of competencies.

During the analysis of the scientific literature on the problem of research, it was found that morality is not an innate quality, it is a property that a person acquires in the process of his formation through communication with society. The sooner a person's familiarization with moral values begins, the stronger and more firmly they will strengthen and establish themselves as personality traits, forming the moral image of a person. 
Taking into account the unconditional advantages of socio-cultural design in relation to solving the problems of moral education of the younger generation, we come to the conclusion that it is advisable to use this type of activity at all levels of school education, starting from the lower grades.

The pilot study was conducted in the period from 2016 to 2021 . It consisted of three stages:

Stage 1 - the ascertaining experiment (2016).

At this stage, the primary diagnosis of the level of moral education of schoolchildren of experimental and control classes was carried out.

Stage 2 - formative (2017-2020).)

At this stage, we organized an approbation of the developed Program of socio-cultural design for schoolchildren in order to test its effectiveness in educating moral qualities in students

Stage 3 - control (2021).

At this stage, a re-diagnosis of the level of moral education of students was carried out, an assessment of the effectiveness of moral education of schoolchildren through sociocultural projects was carried out; methodological recommendations were developed for teachers to work in this direction; prospects for further work were outlined.

The diagnostic results at the third stage of the psychological and pedagogical experiment allow us to judge the positive dynamics of the levels of moral education of schoolchildren, i.e. the effectiveness of the Program of socio-cultural design for schoolchildren developed by us.

Thus, based on the results of the work carried out, it was concluded that effective moral education of schoolchildren through socio-cultural design is possible if:

- a nurturing socio-cultural environment has been created;

- education is carried out taking into account the orientation to the system-activity approach;

- the organization of the design is carried out with the introduction of the student into the world of moral values, with the possibility of moral choice.

\section{References}

Aryabkina, I.V. (2016). Innovative approaches to the spiritual and moral development of the individual. Humanities in Yalta, 3, 49-55. 
Bulavina, D. M. (2007). Project activity in the field of culture as a mechanism for the implementation of cultural policy: abstract of the dissertation of the Candidate of Culturology / Russian Academy of State Services under the President of the Russian Federation. Moscow.

Doronina, N.N., \& Korol, A.I. (2015). Research of moral qualities of youth. Scientific Bulletin: Humanities series, Issue 25, 6 (203), 187-192.

Genisaretsky, O. I. (1986). Social design as a means of active cultural policy. Moscow: Enlightenment.

Khuzina, A.G. (1996). Moral education of primary school children in the family by means of folk pedagogy: (On the example of a Tatar family): Diss.Candidate of Pedagogical Sciences: 13.00.01. Kazan.

Kolinko, I.V. (2011). Designing a socio-cultural space: a culturological approach. Analytics of Cultural Studies, 1(19), 122-124.

Kotova, S.A., Afanasyeva, A.B. (2017). Socio-cultural problems in education: the essence, problems and experience of implementation. Herzen readings. Art education of the child, № 1, 24-34.

Lipsky, I. A., Sikorskaya, L. E. (2013). Social pedagogy: textbook for bachelors. M.: Publishing and Trading Corporation "Dashkov and Co.".

Markov, A. P., Birzhenyuk, G. M. (1997). Fundamentals of socio-cultural design: studies stipend. St. Petersburg: SPBGUP.

Matyash, N.V., Simonenko, V.D. (2007). Project activity of junior schoolchildren: A book for primary school teachers. Moscow: Ventana-Graf.

Mikheeva, N.A. (2008). Socio-cultural design: textbook. St. Petersburg: St. Petersburg State University of Service and Economics.

Ogai, O.A. (2015). Designing socio-cultural projects. Economics and Management-2015: collection of materials of the international scientific conference. Moscow: Rusalliance-Sova, 102-116.

Pakhomov, A.P. (2012). The technique of "Unfinished sentences" by Sachs-Levy as a textbook. Experimental Psychology, vol.14., 99-116.

Rozhkov, M. I., Bayborodova, L. V. (2002). Means of education. Homeroom teacher, 3, 24-30.

State Pedagogical University (2015) Fundamentals of socio-cultural design: an educational and methodological manual. State Public. Scientific-technical. Sib Library. Departments of Russian Academy of Sciences. Novosibirsk: State Pedagogical University.

Sycheva, T.Yu. (2004). Formation of moral values of younger schoolchildren in modern socio-cultural conditions: abstract of the dissertation of the Candidate of Pedagogical Sciences / Barnaul State Pedagogical University. Barnaul.

Troshin, P. L. (2016). Moral education: concept, essence, tasks. Young scientist, 8, 876-884.

Vygotsky, L. S. (1984). Child psychology. M.: Enlightenment.

Vygotsky, L.S. (2000). Psychology. Moscow: April press: EKSMO-press.

Zabbarova, M.G. (2017). Project activities in primary school: educational and methodical manual. Ulyanovsk: FGBOU VPO "ULGPU named after I.N. Ulyanov". 